\title{
Relationships between milk coagulation property traits analyzed with different methodologies
}

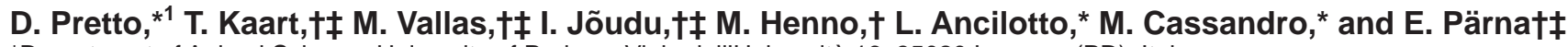 \\ ${ }^{*}$ Department of Animal Science, University of Padova, Viale dell'Università 16, 35020 Legnaro (PD), Italy \\ †Institute of Veterinary Medicine and Animal Sciences, Estonian University of Life Sciences, Kreutzwaldi 1, 51014 Tartu, Estonia \\ ¥Bio-Competence Centre of Healthy Dairy Products, Kreutzwaldi 1, 51014 Tartu, Estonia
}

\begin{abstract}
Milk coagulation properties (MCP) analysis is performed using a wide range of methodologies in different countries and laboratories, using different instruments, coagulant activity in the milk, and type of coagulant. This makes it difficult to compare results and data from different research. The aims of this study were to propose a method for the transformation of values of rennet coagulation time (RCT) and curd firmness $\left(\mathrm{a}_{30}\right)$ and to predict the noncoagulation (NC) probability of milk samples analyzed using different methodologies. Individual milk samples were collected during the morning milking in October 2010 from each of 165 Holstein-Friesian dairy cows in 2 freestall barns in Italy, and sent to 3 laboratories for MCP analysis. For each laboratory, MCP analysis was performed using a different methodology: A, with a computerized renneting meter instrument using 0.051 international milk clotting units $(\mathrm{IMCU}) / \mathrm{mL}$ of coagulant activity; B, with a Lattodinamografo (Foss-Italia, Padova, Italy) using $0.051 \mathrm{IMCU} / \mathrm{mL}$ of coagulant activity; and $\mathrm{C}$, with an Optigraph (Ysebaert, Frépillon, France) using 0.120 $\mathrm{IMCU} / \mathrm{mL}$ of coagulant activity. The relationships between MCP traits were analyzed with correlation and regression analyses for each pair of methodologies. For each MCP trait, 2 regression models were applied: model 1 was a single regression model, where the dependent and independent variables were the same MCP trait determined by 2 different methodologies; in model 2 , both $\mathrm{a}_{30}$ and RCT were included as independent variables. The NC probabilities for laboratories with the highest number of $\mathrm{NC}$ samples were predicted based on the RCT and $\mathrm{a}_{30}$ values measured in the laboratories with lower number of NC samples using logistic regression and receiver operating characteristic analysis. The percentages of $\mathrm{NC}$ samples were $4.2,11.5$, and $0.6 \%$ for $\mathrm{A}, \mathrm{B}$, and $\mathrm{C}$, respectively. The transformation of $\mathrm{MCP}$ traits was more precise with model 1 for $\mathrm{RCT}\left(\mathrm{R}^{2}\right.$ :
\end{abstract}

Received February 14, 2011.

Accepted April 29, 2011.

${ }^{1}$ Corresponding author: denis.pretto@unipd.it
$0.77-0.82)$ than for $\mathrm{a}_{30}\left(\mathrm{R}^{2}: 0.28-0.63\right)$. The application of model 2 was needed when the $\mathrm{C}$ measurements were transformed into the other scales. The analyses of $\mathrm{NC}$ probabilities of milk samples showed that NC samples from one methodology were well distinguishable (with an accuracy of $0.972-0.996$ ) based on the rennet coagulation time measured with the other methodology. A standard definition for MCP traits analysis is needed to enable reliable comparisons between MCP traits recorded in different laboratories and in different animal populations and breeds.

Key words: dairy cattle, milk coagulation property, different method, conversion method

\section{INTRODUCTION}

Milk coagulation properties (MCP) are considered to have an important role in cheese production, mainly because of their relationships with cheese yield (Aleandri et al., 1989; Martin et al., 1997; Wedholm et al., 2006) and cheese quality (Ng-Kwai-Hang et al., 1989; Johnson et al., 2001). Milk coagulation properties have been widely studied in recent years and have been proposed as technological traits for increasing dairy industry efficiency (Ikonen et al., 2004; Jõudu, 2008a). The MCP have been found to have an exploitable additive genetic variation in dairy cattle population, and an estimated heritability range from 15 to $41 \%$ (Ikonen et al., 2004; Cassandro et al., 2008; Vallas et al., 2010). These studies showed that it is possible to improve MCP genetically. Proposals to include these traits in payment systems of milk used for cheese production also exist (De Marchi et al., 2008; Pretto and Cassandro, 2010). Commonly, the main MCP traits studied are milk rennet coagulation time (RCT, min), which is the time from the addition of coagulant to milk until the beginning of coagulation, and curd firmness at $30 \mathrm{~min}$ after coagulant addition $\left(\mathbf{a}_{\mathbf{3 0}}, \mathrm{mm}\right)$. These traits are recorded using alternative systems based on optical, thermal, mechanical, and vibrational methods, which have been comprehensively reviewed by O'Callaghan et al. (2002) and Lucey (2002). Different instruments are available commercially and are currently widely used in research 
institutes to record MCP traits for genetic studies. The computerized renneting meter (CRM; Polo Trade, Monselice, Italy) was used, for example, in the work of Ikonen et al. (2004) and Cassandro et al. (2008); the Optigraph (OPT; Ysebaert, Frépillon, France) was used in the work of Vallas et al. (2010) and the Lattodinamografo (LAT; Foss-Italia, Padova, Italy), which replaced worldwide the now unavailable Formagraph (Foss Electric, Hillerød, Denmark) used, for example, by Ikonen et al. (1999), Jõudu (2008a), and Jõudu et al. (2008b). These instruments measured the same traits but with different principles. The principle of the CRM and the LAT is classified as a mechanical system or rheological method (O'Callaghan et al., 2002) and it is based on the recording of oscillation, which is driven by an electromagnetic field created by the swinging of a small, stainless steel, loop pendulum immersed in the samples of coagulating milk. A survey system measures differences in the electromagnetic field caused by milk coagulation: the greater the extent of coagulation, the smaller the swings of the pendulum. This analysis produces a diagram, as reported by Dal Zotto et al. (2008). On the other hand, measurements made with the OPT are not based on a rheological method but on an optical signal in the near-infrared wavelength. During a coagulation test, the light emitted through the milk gradually weakens, because of changes in the micellar structure of CN. The OPT calculates the coagulation parameters (coagulation time, curd firmness, and speed of aggregation) by means of particular feature points extracted from the optical information acquired in real time (Optigraph User's Manual). Because of the different scales used by the OPT, the value of curd firmness from the optical signal (volts) is transformed into values for $\mathrm{a}_{30}(\mathrm{~mm})$ using a calibration equation (Kübarsepp et al., 2005a) to give comparable data with the same units. All of these instruments use $10 \mathrm{~mL}$ of milk for each sample. In addition to the measurement principle, the MCP analysis can be different because of the final coagulant activity in the milk used to induce the coagulation of samples. The coagulant activity is expressed as international milk clotting units (IMCU) per milliliter of milk. Because rennet is the key enzyme for the enzyme-induced coagulation process of milk, its activity in the milk can affect MCP, as found in several studies that showed that RCT is linearly related with the inverse of the coagulant activity (Brown and Collinge, 1986; Karlsson et al., 2007). Coagulant activity in the milk for MCP analysis has a wide variability reported in the literature. It is in the range of 0.050 to $0.060 \mathrm{IMCU} / \mathrm{mL}$ of milk in Italian research (Zannoni and Annibaldi, 1981; Cassandro et al., 2008; Cecchinato et al., 2009), in the range of 0.110 to 0.150 $\mathrm{IMCU} / \mathrm{mL}$ of milk in Estonian and Finnish studies
(Ikonen et al., 2004; Kübarsepp et al., 2005b; Vallas et al., 2010), and in the range of 0.330 to $0.580 \mathrm{IMCU} / \mathrm{mL}$ in Swedish studies (Hallén et al., 2007; Hallén et al., 2010). In addition, the Swedish works differ from the previous examples in using defatted milk, and during the analysis, the samples were kept at $30^{\circ} \mathrm{C}$ instead of at $35^{\circ} \mathrm{C}$. Furthermore, different types of coagulant were used: calf rennet (Zannoni and Annibaldi, 1981; Cassandro et al., 2008; Cecchinato et al., 2009) or microbial coagulant (Kübarsepp et al., 2005a,b; Vallas et al., 2010). Each country has used a different coagulant activity in the milk, according to their methodology, for MCP analysis. This could be related to the differences in the manufacturing processes and cheese types of national dairy industries. For instance, in the manufacturing process of some of the main Italian Protected Designation of Origin cheeses, such as Grana Padano, Asiago, and Piave, milk coagulant activity in the range 0.035 to $0.045 \mathrm{IMCU} / \mathrm{mL}$ is usually used, whereas in the manufacturing processes of some of the main North European cheeses, such as Edam and Gouda, it is on the order of $0.080 \mathrm{IMCU} / \mathrm{mL}$ (Cheese Dairy Plant Managers: M. Dalla Riva, M. Centeleghe, G. Zambon, L. Maroso, and G. Toniolo for Italian cheeses, and U. Saks and T. Tupasela for North European Gouda and Edam cheeses, personal communication, 2010).

Differences in analyses methodology probably exist, as no standard methods for MCP analyses exist, in contrast to existing standard methods established, for instance, for the determination of total milk-clotting activity of bovine rennets (ISO/IDF, 2007). This situation makes it difficult to compare results from different research that uses different methodologies for the analysis of MCP traits in individual animal samples and bulk milk samples. This could be a technical problem for both the future international genetic evaluation for MCP traits and the application of milk payment systems.

Recently, mid-infrared spectroscopy (MIRS) technology has been proposed as a cheaper method to predict MCP routinely, and for large-scale recording (De Marchi et al., 2009). However, MIRS technology is based on the determination of a calibration equation predicted from spectral data and a reference method and, therefore, the existence of different methodologies for MCP analysis without a method for converting the data could cause further complication.

Some studies have found that comparison between different methodologies for MCP analysis is possible due to strong correlations between MCP measured with these methodologies (Laporte et al., 1998; Kübarsepp et al., 2005a; Klandar et al., 2007). Nevertheless, a critical feature of MCP data are the presence of noncoagulated (NC) milk records; that is, when milk does 
Table 1. Parity, DIM, milk yield, and milk composition of sampled cows $(\mathrm{n}=165)$

\begin{tabular}{lcccc}
\hline Trait & Mean & CV $(\%)$ & Minimum & Maximum \\
\hline Parity & 2.5 & 57.7 & 1 & 7 \\
DIM & 181 & 85.8 & 5 & 703 \\
Milk yield (kg/d) & 32.2 & 27.8 & 7.9 & 56.4 \\
Fat in milk (\%) & 3.93 & 20.0 & 2.04 & 6.91 \\
Protein in milk (\%) & 3.50 & 14.4 & 2.46 & 5.34 \\
SCC (10 ${ }^{3}$ cells/mL) & 200.9 & 179.6 & 8 & 2,945 \\
SCS $^{1}(\mathrm{U})$ & 2.80 & 63.5 & -0.64 & 7.88 \\
pH & 6.68 & 1.0 & 6.45 & 6.88 \\
\hline
\end{tabular}

${ }^{1} \mathrm{SCS}=\left[3+\log _{2}\left(\mathrm{SCC} / 10^{5}\right)\right]$.

not coagulate at all within a standard 30-min testing time (Tyrisevä et al., 2004). Usually, these samples are discarded from statistical analysis and, to our knowledge, no research has been done to compare the probability of NC milk samples from MCP analyses using different methods.

The objectives of this study were to propose (1) a method for the transformation of the values of MCP traits and (2) a method to predict noncoagulation probability of milk samples, analyzed using different methodologies.

\section{MATERIALS AND METHODS}

\section{Milk Sample Collection}

Individual milk samples (4 subsamples per cow) were collected during the morning milking of a test day in October 2010 from 165 Holstein-Friesian dairy cows fed at libitum with TMR in 2 freestall barns in Italy. The samples were processed according to International Committee for Animal Recording procedures (ICAR, 2009) and combined with preservative (Bronopol; Knoll Pharmaceuticals, Nottingham, UK). After collection, milk samples were stored in portable refrigerators (at $4^{\circ} \mathrm{C}$ ) and transferred to the Milk Laboratory of the Veneto region breeders association (ARAV, Padova, Italy; laboratory 1). For MCP analysis, 1 random subsample pack was sent to the milk quality laboratory of Veneto Agricoltura Institute (Thiene, Italy; laboratory 2); 1 random subsample pack was sent by international express shipping to the Laboratory of Milk Quality (Institute of Veterinary Medicine and Animal Sciences, Department of Nutrition and Animal Products Quality) of the Estonian University of Life Sciences (Tartu, Estonia; laboratory 3); and the remaining 2 random subsample packs were kept in laboratory 1 for MCP analysis and the determination of milk fat and protein content (MilkoScan FT 6000; Foss Electric, Hillerød, Denmark), SCC (Fossomatic 5000; Foss Electric), and $\mathrm{pH}$ (pH-Burette 24; Crison Instruments, Barcelona, Spain). The temperature of the samples was main- tained at $4^{\circ} \mathrm{C}$ throughout transport and storage. The subsample for laboratory 3 was sent in an insulated box with cooling bodies to maintain constant temperature and when it arrived, the temperature inside the box was checked to ensure that it was at $4^{\circ} \mathrm{C}$. Because MCP analysis and shipping to the Estonian laboratory 3 were time consuming, MCP analysis was performed in 2 parts: $2 \mathrm{~d}$ ( $50 \%$ of samples) and $3 \mathrm{~d}$ (50\% of samples) after collection. The analyses of the 4 subsamples of a same cow were performed in the same day in all 3 laboratories. The sampled cows were at different stages of lactation (5-703 DIM) and parity (1-7), as shown in Table 1. Milk yield, milk composition, and their variability were representative of Holstein-Friesian performance in the Veneto region (Cassandro et al., 2008; AIA, 2009).

\section{Milk Coagulation Properties}

As the aim of the study was to find the relationship of MCP data in field conditions, using routine recording by different methodologies, each laboratory used their own standard protocol for MCP analysis. The methodologies used in this work are suitable for every single piece of equipment suggested by the producer and already tested in each laboratory over the years.

Three methodologies of analysis were identified as A, B, and C. In method A, a CRM and standard rennet were used (Hansen standard $160 \mathrm{IMCU} / \mathrm{mL}$, with $80 \%$ chymosin and $20 \%$ pepsin; Pacovis Amrein AG, Bern, Switzerland), which were diluted in distilled water $(1.6: 100 \mathrm{vol} / \mathrm{vol})$. In method B, the same coagulant with the same dilution as in method A was used, and measurement was made using an LAT. In method C, the instrument was the OPT and a microbial coagulant (Milase MRS, $600 \mathrm{IMCU} / \mathrm{mL}$; CSK Food Enrichment B.V., Leeuwarden, the Netherlands) was diluted in distilled water $(1: 100 \mathrm{vol} / \mathrm{vol})$. Fresh coagulant solution was prepared every $3 \mathrm{~h}$. In each laboratory, milk samples for MCP were removed from the refrigerator 15 min before analysis and heated in a water bath to $35^{\circ} \mathrm{C}$. Once $35^{\circ} \mathrm{C}$ was reached, $200 \mu \mathrm{L}$ of coagulant solution 
was added to $10 \mathrm{~mL}$ of milk and the analysis began within $15 \mathrm{~s}$. According to these protocols, final coagulant activities in the milk were: $0.051 \mathrm{IMCU} / \mathrm{mL}, 0.051$ $\mathrm{IMCU} / \mathrm{mL}$, and $0.120 \mathrm{IMCU} / \mathrm{mL}$, for the $\mathrm{A}, \mathrm{B}$, and $\mathrm{C}$ methodologies, respectively.

The MCP was determined at $35^{\circ} \mathrm{C}$ and completed within $30 \mathrm{~min}$ after the addition of the coagulating enzyme to samples. An attempt to use uniform analysis protocol was made with 60 random samples, for which the coagulant solution was prepared to produce equal coagulant activity in the milk and using the same coagulant. These 60 samples were analyzed by CRM, LAT, and OPT by using $0.051 \mathrm{IMCU} / \mathrm{mL}$ of coagulant activity for all equipment and rennet Hansen standard 160 (methodology $\mathrm{C}^{*}$ ).

\section{Statistical Analysis}

Two MCP traits were measured: RCT and $\mathrm{a}_{30}$. The OPT signal for $\mathrm{a}_{30}$ (in volts) was transformed into values for $\mathrm{a}_{30}(\mathrm{~mm})$ using the calibration equation proposed by Kübarsepp et al. (2005a). Samples that did not coagulate within 30 min were classified as NC.

Only samples that coagulated (CO) with all methodologies were used to compare the mean values and variances of MCP traits, and to estimate the relationships between MCP traits. The proportions of NC samples, mean values, and variances of MCP traits with different methodologies were compared with the McNemar test for matched pairs, the paired samples $t$-test, and the F-test. The relationships between MCP traits were analyzed with correlation and regression analyses for each pair of methodologies. Two regression models were applied for each MCP trait: model 1 was a single regression model where the dependent and independent variables were the same MCP trait in 2 different methodologies, whereas in model 2 , both $\mathrm{a}_{30}$ and RCT were included as independent variables. Additionally, the effects of sample age, farm, parity of cows, and DIM on the parameters of regression analysis were tested.

The NC probabilities for laboratories with the highest number of NC samples were predicted based on the $\mathrm{RCT}$ and $\mathrm{a}_{30}$ values measured in the laboratories with lower number of $\mathrm{NC}$ samples using logistic regression and receiver operating characteristic (ROC) analysis. The ROC analysis was used to find the optimal RCT and $\mathrm{a}_{30}$ values to discriminate the $\mathrm{NC}$ and $\mathrm{CO}$ samples. Moreover, the corresponding noncoagulation probabilities were estimated and the percentage of correctly classified NC samples (sensitivity), correctly classified CO samples (specificity), and the overall probability of concordance (area under the ROC curve) were calculated.

A 0.05 level of significance was used. All statistical analyses were performed using SAS software (version
9.2; SAS Institute Inc., Cary, NC) and figures were drawn from R software (version 2.10.1; http://www. r-project.org).

\section{RESULTS AND DISCUSSION}

\section{Descriptive Statistics}

The number and percentage of $\mathrm{CO}$ and $\mathrm{NC}$ samples, and descriptive statistics of MCP traits measured by different methodologies, are presented in Table 2. The number (and percentage) of NC samples were $7(4.2 \%)$, $19(11.5 \%)$, and $1(0.6 \%)$ for the methodologies A, B, and $\mathrm{C}$, respectively. All $\mathrm{NC}$ samples using A did not coagulate at the same time as $\mathrm{B}$, whereas the only $\mathrm{NC}$ sample using $\mathrm{C}$ coagulated both with $\mathrm{A}$ and $\mathrm{B}$. This could be related to the different principles of analysis for OPT than for CRM and LAT instruments and, as will be discussed later, differences in the context of the different coagulant activity used and type of coagulant in the different methodologies.

The percentages of $\mathrm{NC}$ samples in this study for A and $\mathrm{B}$ were comparable with those found in Cassandro et al. (2008) and Ikonen et al. (2004) who used CRM and found $\mathrm{NC}$ percentages of $9.7 \%$ and $13.2 \%$, respectively. The $\mathrm{C}$ results were similar to those of Vallas et al. (2010), where, using the same equipment (OPT), $0.3 \%$ of samples did not coagulate within 30 min after the addition of coagulant.

The means of RCT measured on the CO samples differed significantly between the 3 methodologies (Table 2 ). On average, the RCT values measured with $\mathrm{C}$ were much lower than those measured with both $\mathrm{A}$ and $\mathrm{B}$ (8.0 min compared with 15.6 and $18.2 \mathrm{~min}$ ). This large difference is probably due to the higher concentration of coagulant in $\mathrm{C}$ compared with both $\mathrm{A}$ and $\mathrm{B}$. The variation coefficients for RCT were 23,24 , and $25 \%$ for A, $\mathrm{B}$, and $\mathrm{C}$, respectively, and the standard deviation was significantly lower for the analyses of $\mathrm{C}$ compared with both $\mathrm{A}$ and $\mathrm{B}$. The means of $\mathrm{a}_{30}$ were similar for both $\mathrm{B}$ and C (29.6 and $29.7 \mathrm{~mm}$, respectively), whereas for A, the mean of $\mathrm{a}_{30}$ was significantly higher, at $36.2 \mathrm{~mm}$. The standard deviation of $\mathrm{a}_{30}$ was significantly higher for the analyses using B compared with both $\mathrm{C}$ and $\mathrm{A}$.

In general, RCT and $\mathrm{a}_{30}$ values of the samples analyzed with A were similar to those reported by Cassandro et al. (2008) for Italian Holsteins, and for C to the values reported by Vallas et al. (2010) in the Estonian Holstein population.

These results confirm that the MCP measured with different methodologies, with different instruments and coagulant activity, may give considerably different values, and to use them in joint genetic evaluation, some transformation into one common scale is needed. 
Table 2. Description of methods used for determination of milk coagulation properties (MCP), number of noncoagulated samples, and descriptive statistics for milk rennet coagulation time (RCT, min) and curd firmness $\left(\mathrm{a}_{30}, \mathrm{~mm}\right)$

\begin{tabular}{|c|c|c|c|c|}
\hline Item & \multicolumn{4}{|c|}{ Method } \\
\hline Coagulant & Hansen standard $160^{5}$ & Hansen standard 160 & Milase MRS $600^{6}$ & Hansen standard 160 \\
\hline $\begin{array}{l}\text { Coagulant activity } \\
\text { (IMCU/mL of milk) }\end{array}$ & 0.051 & 0.051 & 0.120 & 0.051 \\
\hline \multicolumn{5}{|l|}{ No. $^{7}$} \\
\hline $\mathrm{NC}$ & $7(4.2 \%)^{\mathrm{b}}$ & $19(11.5 \%)^{\mathrm{a}}$ & $1(0.6 \%)^{b}$ & $30(50.0 \%)$ \\
\hline \multicolumn{5}{|l|}{$\mathrm{RCT}^{8}(\min )$} \\
\hline Mean & $15.6^{\mathrm{b}}$ & $18.2^{\mathrm{a}}$ & $8.0^{\mathrm{c}}$ & 28.2 \\
\hline $\mathrm{SD}$ & $4.0^{\mathrm{a}}$ & $4.5^{\mathrm{a}}$ & $1.8^{\mathrm{b}}$ & \\
\hline \multicolumn{5}{|l|}{$\mathrm{a}_{30}^{8}(\mathrm{~mm})$} \\
\hline Mean & $36.2^{\mathrm{a}}$ & $29.6^{\mathrm{b}}$ & $29.7^{\mathrm{b}}$ & 5.1 \\
\hline $\mathrm{SD}$ & $9.9^{\mathrm{b}}$ & $12.9^{\mathrm{a}}$ & $8.5^{\mathrm{b}}$ & \\
\hline
\end{tabular}

${ }^{\mathrm{a}-\mathrm{c}}$ Proportions of noncoagulated samples, means, and SD within a row for A, B, and $\mathrm{C}$ methodologies with different superscripts differ $(P<$ $0.05)$.

${ }^{1} 60$ random samples were analyzed with this method.

${ }^{2}$ By Polo Trade (Monselice, Italy).

${ }^{3}$ By Foss-Italia (Padova, Italy).

${ }^{4}$ By Ysebaert (Frépillon, France).

${ }^{5}$ Produced by Pacovis Amrein AG (Bern, Switzerland).

${ }^{6}$ Produced by CSK Food Enrichment B.V. (Leeuwarden, the Netherlands).

${ }^{7} \mathrm{CO}=$ coagulated samples; $\mathrm{NC}=$ noncoagulated samples.

${ }^{8}$ Only coagulated samples with A, B, and C methodologies $(\mathrm{n}=145)$.

\section{Correlation and Regression Analysis}

The RCT and $\mathrm{a}_{30}$ were strongly and negatively correlated in the analyses with $\mathrm{A}$ and $\mathrm{B}(\mathrm{r}=-0.79$ and $\mathrm{r}=$ -0.86 , respectively; Table 3 ). The correlation between RCT and $\mathrm{a}_{30}$ measured with $\mathrm{C}$ was significantly lower but still negative $(\mathrm{r}=-0.23)$. These results are logical, as the time for instrumental assessment of MCP through current milk coagulation meters is restricted to $30 \mathrm{~min}$ from the time of coagulant addition, and a later start of curd firmness leaves less time for the firmness process, which results in a weaker curd (Dal Zotto et al., 2008). Similar results have been presented in other studies (Kübarsepp et al., 2005b; Cassandro et al., 2008; Vallas et al., 2010).

Strong positive linear relationships were found between RCT values measured with the different methodologies (correlation coefficients ranged from 0.88 to 0.91; Table 3). The $\mathrm{a}_{30}$ values measured with different methodologies are less related than the RCT. This is in agreement with less favorable values of analytical repeatability and reproducibility for $\mathrm{a}_{30}$ compared with RCT reported by Dal Zotto et al. (2008) for measures of MCP traits obtained using CRM. The strongest correlation was found between $\mathrm{A}$ and $\mathrm{B}$ measured $\mathrm{a}_{30}$ values $(\mathrm{r}=0.79$; Table 3$)$, whereas the correlation of $\mathrm{a}_{30}$ measured with $\mathrm{C}$ and those measured with $\mathrm{A}$ and $\mathrm{B}$ were moderate $(\mathrm{r}=0.53$ and $\mathrm{r}=0.66$, respectively).
Figure 1 and Figure 2 present the results of regression analysis with model 1 for RCT and $\mathrm{a}_{30}$, respectively. The high goodness-of-fit values of the regression between RCT data ( $\mathrm{R}^{2}$ ranged from 0.77 to 0.82$)$ allows the reliable conversion of $\mathrm{RCT}$ values between laboratories and instruments. Additionally, including the $\mathrm{a}_{30}$ as an independent variable (model 2), did not increase the coefficient of determination value by more than 0.01 to 0.03 . The transformation of $\mathrm{a}_{30}$ values between pairs of methodologies was most reliable between $\mathrm{A}$ and $\mathrm{B}$

Table 3. Pearson correlation coefficients for milk rennet coagulation time $(\mathrm{RCT}, \mathrm{min})$ and curd firmness $\left(\mathrm{a}_{30}, \mathrm{~mm}\right)$ measured with the three different methodologies (A, B, and $\mathrm{C}$ subscripts) for the coagulated samples with all methodologies $(\mathrm{n}=145 ; P<0.05 \text { for all correlations })^{1}$

\begin{tabular}{lccccc}
\hline Trait & $\mathrm{RCT}_{\mathrm{B}}$ & $\mathrm{RCT}_{\mathrm{C}}$ & $\mathrm{a}_{30 \mathrm{~A}}$ & $\mathrm{a}_{30 \mathrm{~B}}$ & \multicolumn{1}{c}{$\mathrm{a}_{30 \mathrm{C}}$} \\
\hline $\mathrm{RCT}_{\mathrm{A}}$ & \multirow{2}{*}{0.906} & 0.902 & -0.787 & -0.735 & -0.297 \\
$\mathrm{RCT}_{\mathrm{B}}$ & & 0.879 & -0.742 & -0.862 & -0.375 \\
$\mathrm{RCT}_{\mathrm{C}}$ & & & -0.627 & -0.683 & -0.233 \\
$\mathrm{a}_{30 \mathrm{~A}}$ & & & & 0.793 & 0.533 \\
$\mathrm{a}_{30 \mathrm{~B}}$ & & & & & 0.657 \\
\hline
\end{tabular}

${ }^{1}$ Methods: A: computerized renneting meter (Polo Trade, Monselice, Italy) and $0.051 \mathrm{IMCU} / \mathrm{mL}$ of milk of Hansen standard (160 IMCU/ $\mathrm{mL}$, with $80 \%$ chymosin and $20 \%$ pepsin; Pacovis Amrein AG, Bern, Switzerland); B: Lattodinamografo (Foss-Italia, Padova, Italy) and $0.051 \mathrm{IMCU} / \mathrm{mL}$ of milk of Hansen standard (160 IMCU $/ \mathrm{mL}$, with 80\% chymosin and 20\% pepsin; Pacovis Amrein AG); C: Optigraph (Ysebaert, Frépillon, France) and $0.120 \mathrm{IMCU} / \mathrm{mL}$ of milk of Milase de Man, Rogosa, and Sharpe (MRS; $600 \mathrm{IMCU} / \mathrm{mL}$; CSK Food Enrichment B.V., Leeuwarden, the Netherlands). 
$\left(\mathrm{R}^{2}=0.63\right.$; Figure 2$)$. Applying the models with both $\mathrm{a}_{30}$ and RCT as independent variables (model 2) the reliability of predictions for conversion of the data into $\mathrm{C}$ using both $\mathrm{a}_{30}$ and RCT traits (model 2) increased by almost double $\left(\mathrm{R}^{2}=0.55\right.$ and $\mathrm{R}^{2}=0.73$, the predicting of $\mathrm{a}_{30}$ measured with $\mathrm{A}$ and $\mathrm{B}$, respectively). The transformation of curd firmness values in these cases should include both $\mathrm{a}_{30}$ and RCT data (equations not shown in figure: $\mathrm{a}_{30 \mathrm{~A}}=44.74+0.473 \mathrm{a}_{30 \mathrm{C}}-2.839 \mathrm{RCT}_{\mathrm{C}} ; \mathrm{a}_{30}$ $\left.{ }_{\mathrm{B}}=37.09+0.797 \mathrm{a}_{30 \mathrm{C}}-3.921 \mathrm{RCT}_{\mathrm{C}}\right)$.

\section{Prediction of Noncoagulation Probability}

The logistic regression and ROC analysis results for RCT in 3 pair combinations of methodologies are presented in Figure 3. The probabilities of NC samples with $\mathrm{B}$ were highly predictable based on the milk rennet coagulation time measured with either $\mathrm{C}$ or $\mathrm{A}$. Also, the probabilities of $\mathrm{NC}$ samples in A were highly predictable based on the milk rennet coagulation time measured in $\mathrm{C}$. The optimal RCT values to distinguish $\mathrm{NC}$ and $\mathrm{CO}$ samples resulted in the probabilities of concordance with empirical data of between 0.972 and 0.996, whereby the NC samples were determined with a probability of 1.000 and coagulated samples with probabilities of 0.89 to 0.98 (Figure 3). Furthermore, the prediction accuracy did not increase by taking into account the curd firmness values. Predicting the NC probability based on the curd firmness only resulted in less accurate predictions.

\section{Uniform Coagulant Activity}

Additionally, analyses were made with 60 randomly chosen samples (from 165 initial samples) using OPT with the same coagulant activity and the same coagulant as was used in the A and B methodologies (Hansen standard 160, $0.051 \mathrm{IMCU} / \mathrm{mL}$; $\mathbf{C}^{*}$; Table 2). The milk yield and composition values of the 60 selected samples did not differ significantly from the corresponding values of the whole data set. As a result, we recorded 30 $\mathrm{NC}$ samples; the percentage of $\mathrm{NC}$ samples with $\mathrm{C}^{*}$ increased from an initial $0.6 \%$ in $\mathrm{C}$ to $50 \%$ (Table 2). An explanation for this increase in $\mathrm{NC}$ samples could be that coagulant activity or type of coagulant (calf rennet vs. microbial coagulant) used in $\mathrm{A}$ and $\mathrm{B}$ are unsuitable for the Optigraph instrument.

The random sample contained $6 \mathrm{NC}$ samples from B and $5 \mathrm{NC}$ samples from the A analyses, and of all of these samples, none also coagulated with $\mathrm{C}^{*}$.

The average RCT of $\mathrm{CO}$ samples for $\mathrm{C}^{*}$ was 21.0 min, which is significantly higher compared with the initial RCT measured with $\mathrm{C}(8.0 \mathrm{~min})$. The average $\mathrm{a}_{30}$ of the $\mathrm{CO}$ samples was $5.9 \mathrm{~mm}$, which is signifi- cantly lower compared with the initial $\mathrm{a}_{30}$ measured with C $(29.7 \mathrm{~mm})$.

Furthermore, we tried to distinguish the $\mathrm{CO}$ and $\mathrm{NC}$ samples of $\mathrm{C}^{*}$ based on the MCP of the same samples measured with either A or B. The ROC analyses showed that more than $95 \%$ of the samples were correctly classifiable based on the RCT, and more than $82 \%$ based on the $\mathrm{a}_{30}$. The probability of noncoagulated samples seems to be quite well predictable irrespective of the instrument used, especially based on the RCT.

\section{Possible Causes of Difference for MCP Traits}

Three 3 main reasons certainly exist that could cause a difference in the values of the MCP traits: the first is the different equipment used in each laboratory; the second is the difference in coagulant activity in the milk to induce coagulation, and the third is the type of coagulant used.

In this study, it was difficult to distinguish the effect of instrument and coagulant effects on the MCP for all of the methodologies. The instrument effect is clear in the A (CRM) and B (LAT) comparison because, in these analyses, the same coagulant activity and type of coagulant was used. The CRM had different sensitivity compared with the LAT, because, in the CRM analyses, the number of NC samples was smaller, the milk rennet coagulation time was shorter, and the curd firmness was thicker. Nevertheless, the working principles of the CRM and the LAT are similar enough to allow reliable transformation of MCP onto one scale. The differences in the OPT working principles, in comparison with the 2 other types of equipment investigated, could be the cause for the weak correlation of $\mathrm{C}$ with the other 2 methodologies, and a low prediction ability in the conversion of $\mathrm{a}_{30}$ in this methodology. Related to this, the type of coagulant used could also affect the comparison among methodologies. For instance, Jacob et al. (2010) found that a lower concentration of calf rennet was necessary compared with that of a microbial coagulant to ensure a specified curd-cutting time. Even in the case of a coagulant effect, a strong relationship should exist between the same MCP traits with different instruments, assuming that the instruments measure the same aspects of the coagulation process. The RCT indeed showed a strong relationship between measurements from different laboratories, even when different methodologies were used. On the contrary, the moderate correlations between $\mathrm{a}_{30}$ measured with LAT or CRM and OPT are probably due to the different principles of the instruments, as the LAT and the CRM are based on the direct measurement of viscoelasticity, whereas the OPT measures are indirect and based on the optical signal. O'Callaghan et al. (2002) reported 


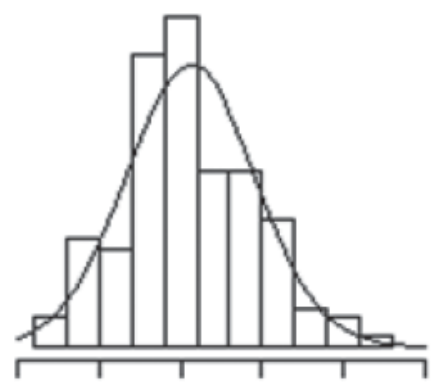

$\begin{array}{llllll}5 & 10 & 15 & 20 & 25 & 30\end{array}$

$\mathrm{RCT}_{\mathrm{A}}$

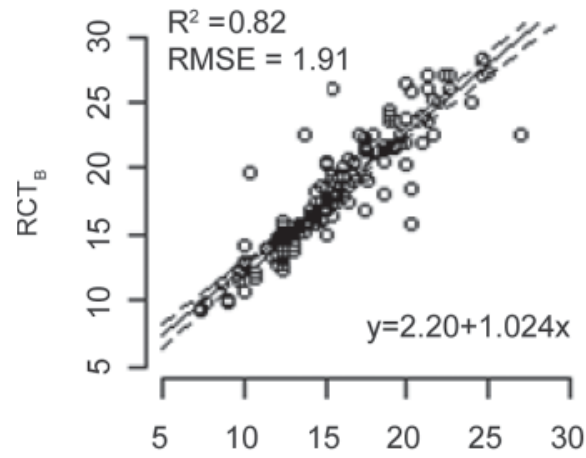

$\mathrm{RCT}_{\mathrm{A}}$

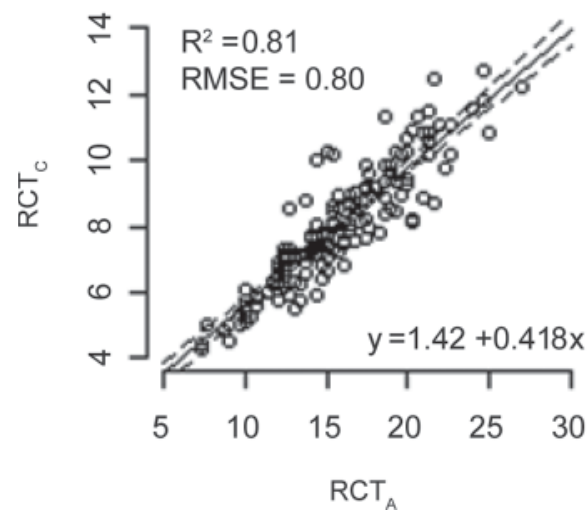

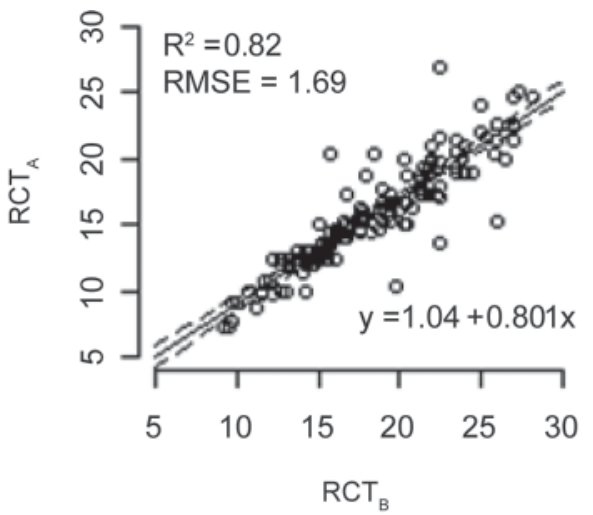
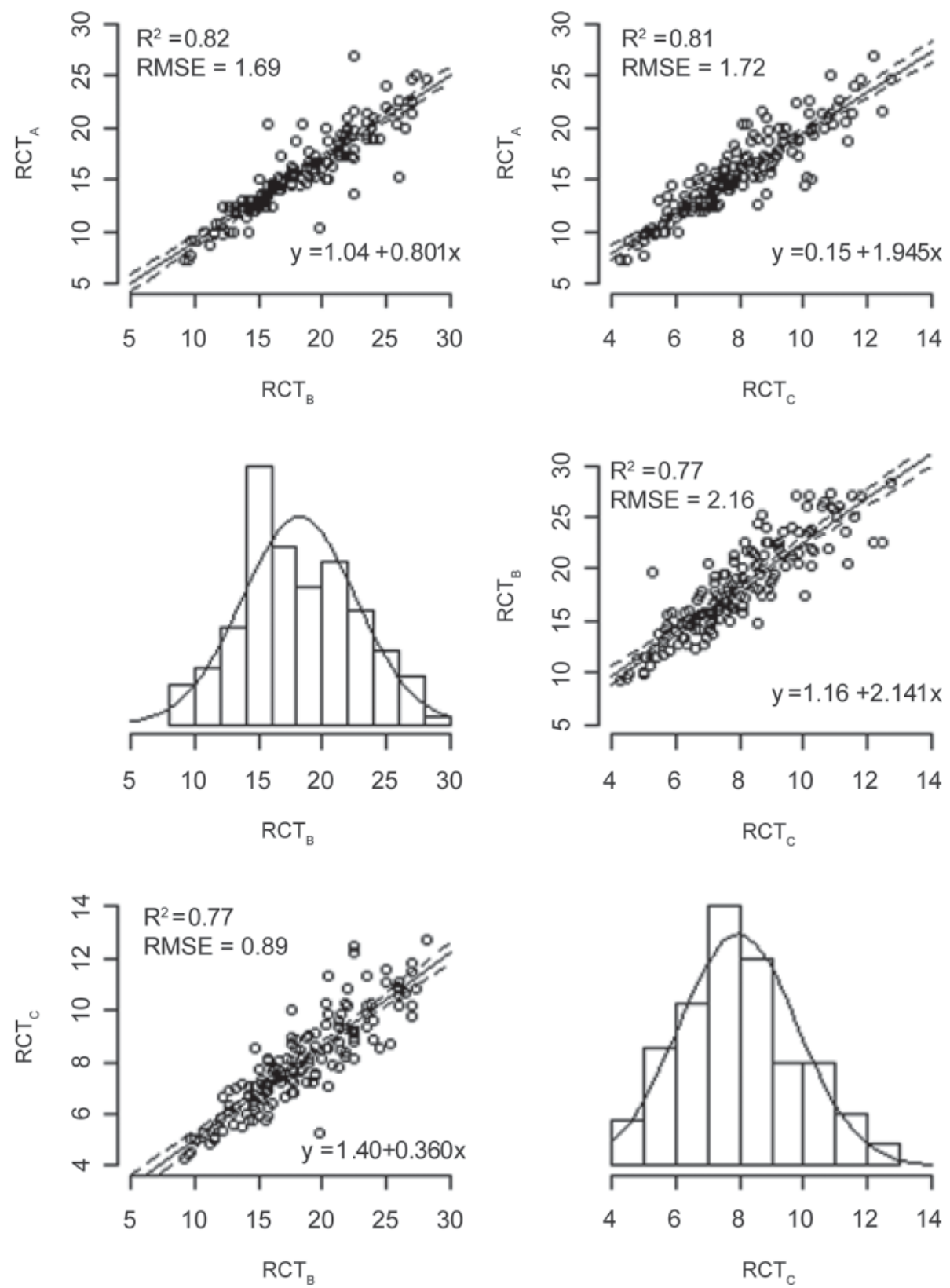

Figure 1. Distribution, regression parameters and regression line (solid line) shown with $95 \%$ confidence interval (dashed lines) of milk rennet coagulation time (RCT, min) measured with 3 different methodologies (A, B, and C subscripts) for the coagulated samples with all methodologies $(\mathrm{n}=145 ; P<0.05$ for all models). Methods: A: computerized renneting meter (Polo Trade, Monselice, Italy) and $0.051 \mathrm{IMCU} / \mathrm{mL}$ of milk of Hansen standard (160 IMCU/mL, with $80 \%$ chymosin and $20 \%$ pepsin; Pacovis Amrein AG, Bern, Switzerland); B: Lattodinamografo (FossItalia, Padova, Italy) and $0.051 \mathrm{IMCU} / \mathrm{mL}$ of milk of Hansen standard (160 IMCU/mL, with $80 \%$ chymosin and $20 \%$ pepsin; Pacovis Amrein AG); C: Optigraph (Ysebaert, Frépillon, France) and $0.120 \mathrm{IMCU} / \mathrm{mL}$ of milk of Milase de Man, Rogosa, and Sharpe (MRS; 600 IMCU/mL; CSK Food Enrichment B.V., Leeuwarden, the Netherlands). RMSE = root mean square error.

that whereas the characteristic of optical change accompanies coagulation, the correlation between optical signal and curd tension is, to some extent, confounded by the rate of reaction, indicating that changes in optical properties are not exclusively related to curd firming. This was also found by Vallas et al. (2010) in whose study genetic and phenotypic correlations between milk coagulation time and curd firmness measured by OPT were different from those reported in previous studies using other equipment, indicating that coagulation aspects measured by OPT, compared with mechanical systems, may be different.

It is supposed from the results of samples analyzed with uniform coagulant activity (methodology $\mathrm{C}^{*}$ ) 


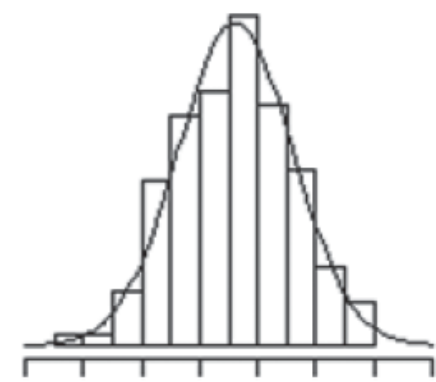

$\begin{array}{lllllllll}0 & 10 & 20 & 30 & 40 & 50 & 60 & 70\end{array}$

$\mathrm{a}_{30 \mathrm{~A}}$

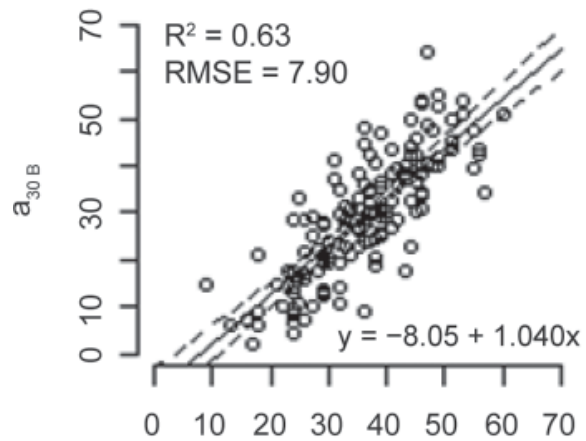

$\mathrm{a}_{30 \mathrm{~A}}$

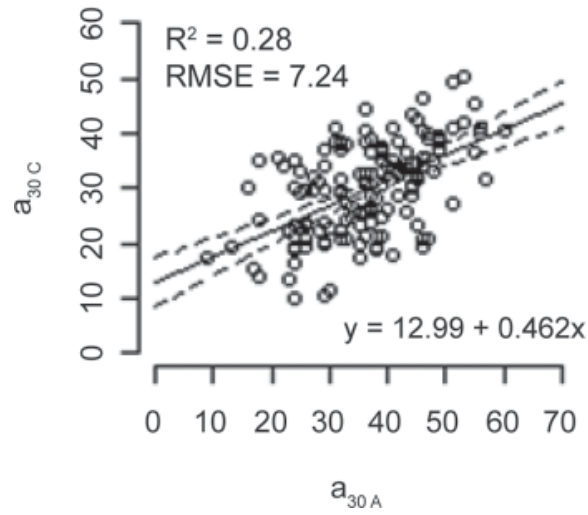

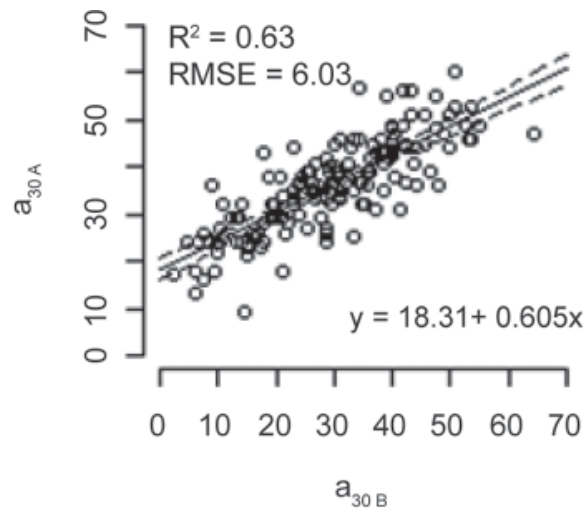
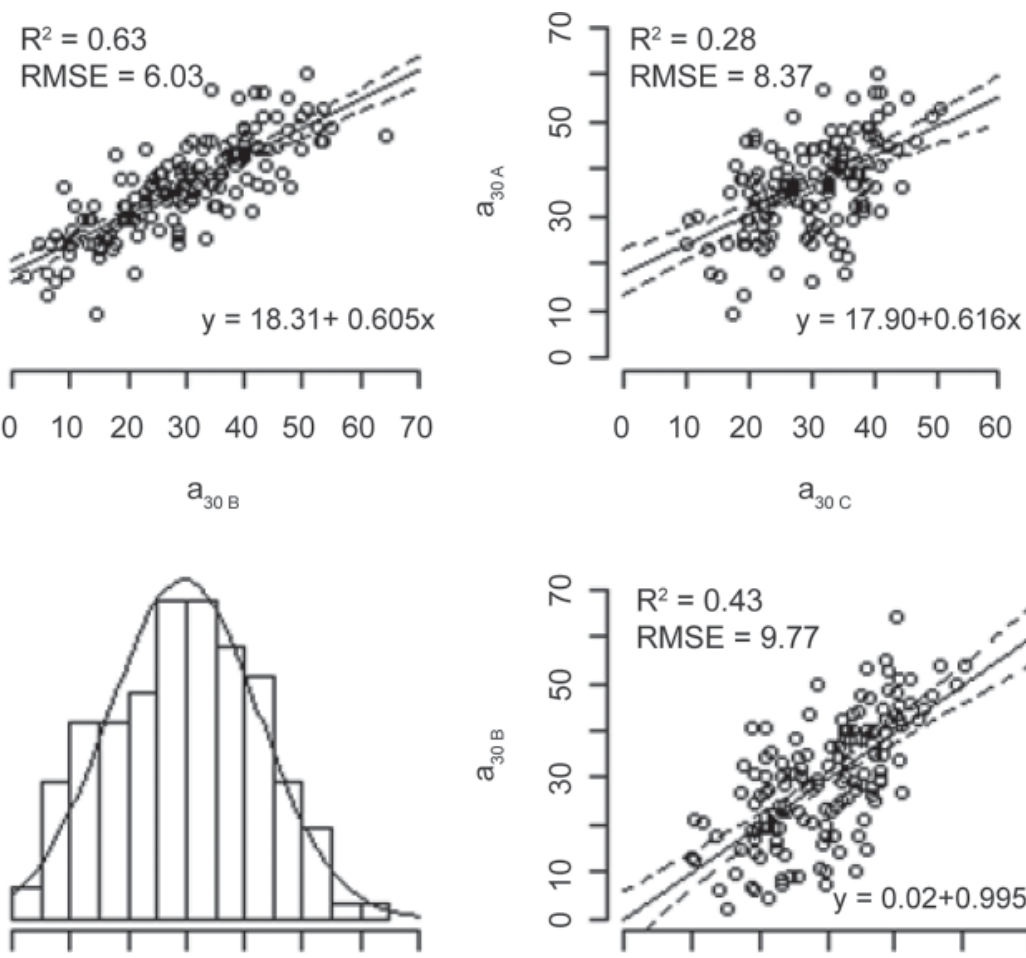

$\begin{array}{llllllll}0 & 10 & 20 & 30 & 40 & 50 & 60 & 70\end{array}$

$\mathrm{a}_{30 \mathrm{~B}}$

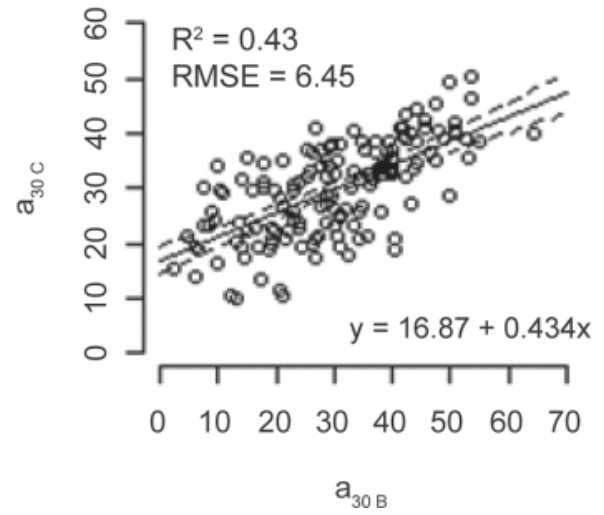

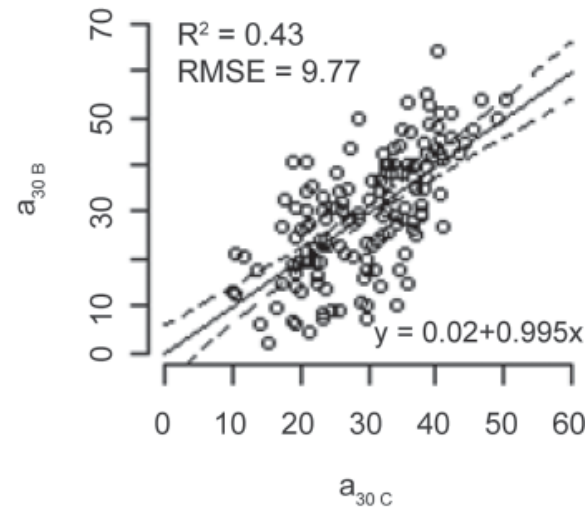

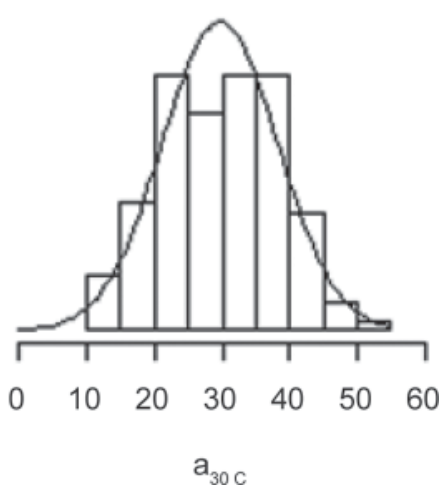

Figure 2. Distribution, regression parameters and regression line (solid line) shown with $95 \%$ confidence interval (dashed lines) of curd firmness $\left(\mathrm{a}_{30}, \mathrm{~min}\right)$ measured with 3 different methodologies $(\mathrm{A}, \mathrm{B}$, and $\mathrm{C}$ subscripts $)$ for the coagulated samples with all methodologies $(\mathrm{n}=145$; $P<0.05$ for all models). Methods: A: computerized renneting meter (Polo Trade, Monselice, Italy) and 0.051 IMCU/mL of milk of Hansen standard (160 IMCU/mL, with $80 \%$ chymosin and $20 \%$ pepsin; Pacovis Amrein AG, Bern, Switzerland); B: Lattodinamografo (Foss-Italia, Padova, Italy) and $0.051 \mathrm{IMCU} / \mathrm{mL}$ of milk of Hansen standard (160 IMCU/mL, with $80 \%$ chymosin and 20\% pepsin; Pacovis Amrein AG); C: Optigraph (Ysebaert, Frépillon, France) and 0.120 IMCU/mL of milk of Milase de Man, Rogosa, and Sharpe (MRS; $600 \mathrm{IMCU} / \mathrm{mL}$; CSK Food Enrichment B.V., Leeuwarden, the Netherlands). RMSE = root mean square error.

that, by decreasing the coagulant activity in the OPT analyses, it should be possible to achieve the same RCT as with $\mathrm{A}$ or $\mathrm{B}$, but concurrently, the $\mathrm{a}_{30}$ values will decrease considerably. Moreover, the relationships between MCP measured with $\mathrm{C}^{*}$ and other methodologies decreased compared with $\mathrm{C}$, especially for $\mathrm{a}_{30}$. From these analyses it can be concluded that more coagulant is needed for the OPT than the LAT and the CRM, because a higher activity of coagulant in the milk is needed to cause differences in the optical signal. In addition, higher coagulant activity improves the coagulation process, and the variability of the MCP decreases. This can be deduced from the smaller variability of the $\mathrm{MCP}$ and the smaller number of NC samples in the 
a)

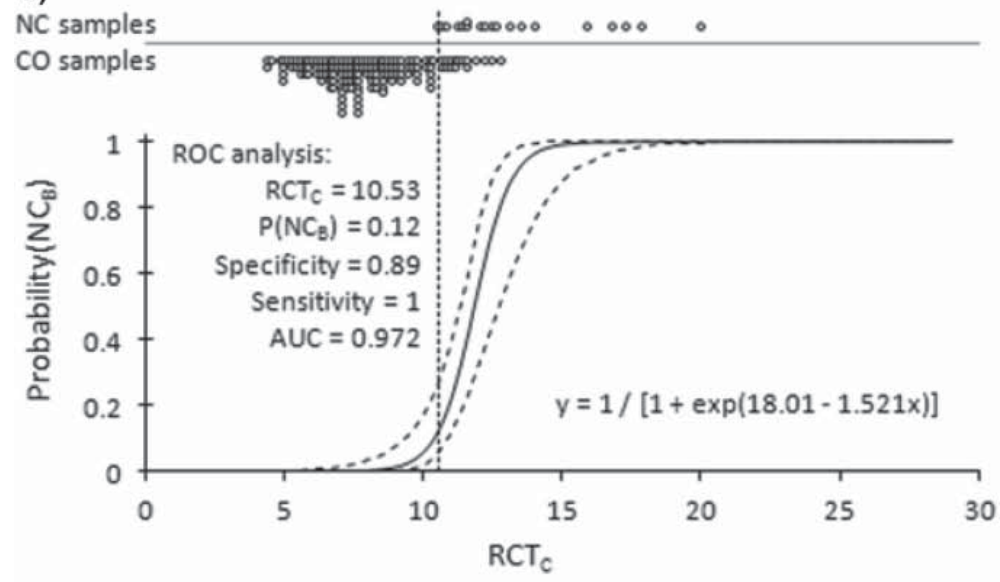

b)

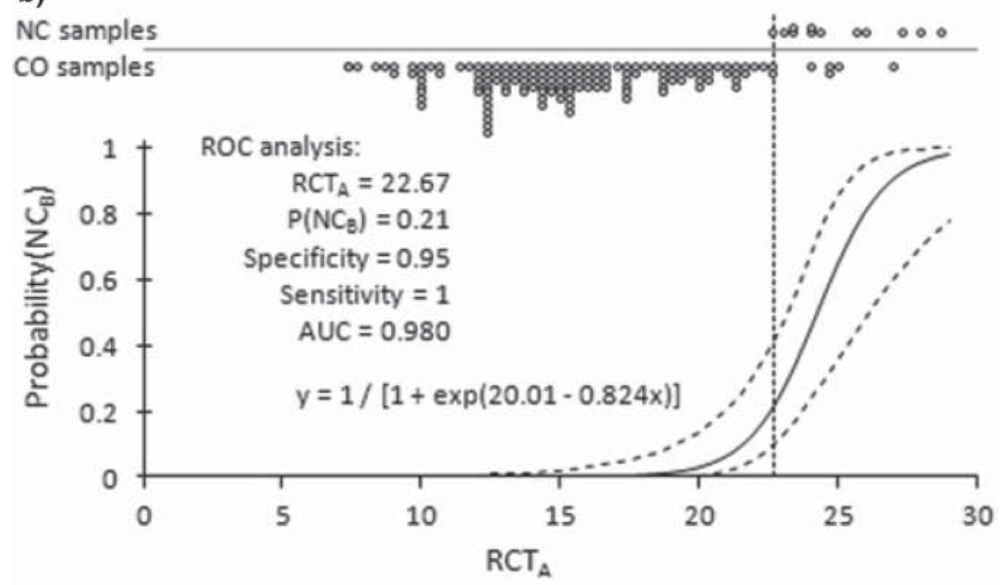

c)

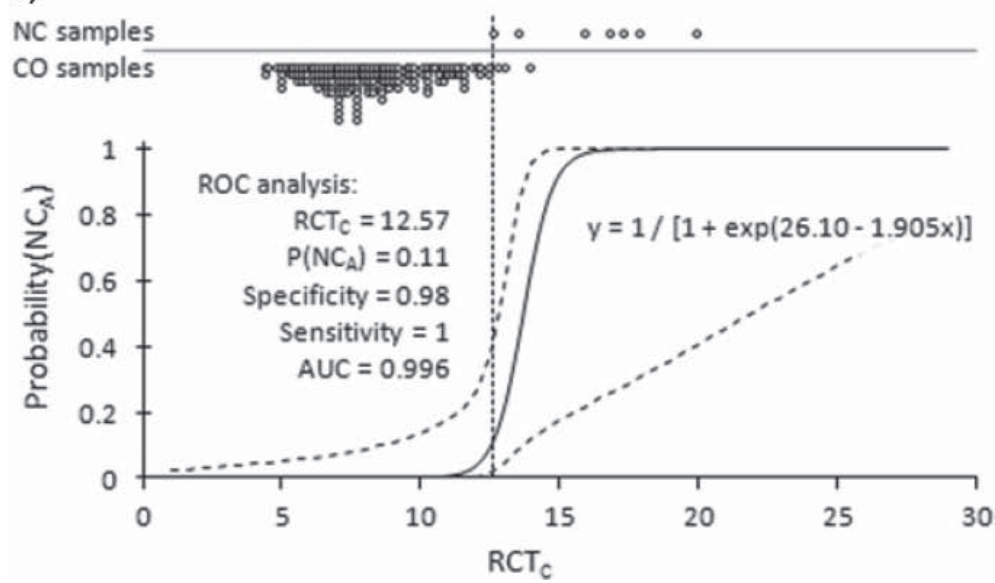

Figure 3. Results of logistic regression analyses predicting (a) the probability of noncoagulated (NC) samples in method B when the analyses for milk rennet coagulation time (RCT, min) are performed by method $\mathrm{C}$, (b) the probability of NC samples in method B when the analyses for $\mathrm{RCT}$ are performed by method A, and (c) the probability of NC samples in method A when the analyses for RCT are performed by method C. The distribution of NC and coagulated (CO) samples, and the logistic regression curve (solid line) with 95\% confidence interval (dashed lines) are shown. The results of the receiver operating characteristic (ROC) analyses presented are the optimal RCT value to distinguish NC and CO samples (vertical dotted line), corresponding noncoagulation probability $[\mathrm{p}(\mathrm{NC})]$, specificity and sensitivity, and area under the ROC curve (AUC). Methods: A: computerized renneting meter (Polo Trade, Monselice, Italy) and $0.051 \mathrm{IMCU} / \mathrm{mL}$ of milk of Hansen standard (160 IMCU/ mL, with $80 \%$ chymosin and $20 \%$ pepsin; Pacovis Amrein AG, Bern, Switzerland); B: Lattodinamografo (Foss-Italia, Padova, Italy) and 0.051 $\mathrm{IMCU} / \mathrm{mL}$ of milk of Hansen standard (160 IMCU/mL, with $80 \%$ chymosin and $20 \%$ pepsin; Pacovis Amrein AG); C: Optigraph (Ysebaert, Frépillon, France) and $0.120 \mathrm{IMCU} / \mathrm{mL}$ of milk of Milase de Man, Rogosa, and Sharpe (MRS; $600 \mathrm{IMCU} / \mathrm{mL}$; CSK Food Enrichment B.V., Leeuwarden, the Netherlands). 
initial OPT analyses in which higher coagulant activity was used.

\section{CONCLUSIONS}

The method proposed provides the opportunity to convert MCP data obtained by different methodologies into comparable data sets across different methodologies. The results of this study have shown that MCP traits analyzed with different methodologies have significantly different values due to the diversity of the instruments and the coagulant activity. The type of coagulant could have a further effect, as 2 different coagulants were used: calf rennet that contains 2 milk-clotting enzymes and one of microbial origin, which contained a single milk-clotting enzyme; but more investigations are needed to clarify this effect. The transformation of the other methodologies is more precise for $\mathrm{RCT}$ $\left(\mathrm{R}^{2}: 0.77-0.82\right)$ than for $\mathrm{a}_{30}\left(\mathrm{R}^{2}: 0.28-0.63\right)$. The $\mathrm{a}_{30}$ was transformable, with moderate accuracy, between $\mathrm{A}$ and $\mathrm{B}$, whereas the $\mathrm{C}$ measurements could be transformed into the other scales with moderate accuracy only when both curd firmness and rennet coagulation time were included in the model. The method proposed for harmonization of noncoagulation probabilities of milk samples showed that NC samples from one methodology were highly predictable based on the rennet coagulation time measured with another methodology. This work pointed out the problem that a standard definition for MCP traits analysis is needed to enable reliable comparisons between MCP traits recorded in different laboratories, and in different animal populations and breeds.

\section{ACKNOWLEDGMENTS}

The authors acknowledge financial support by Distretto Lattiero Caseario del Veneto (Venice, Italy): TRACCIABIANCA project (DGR 2549, 04/08/2009, Mis. 2A - Regione Veneto) and PRIN project 2007-prot. 2007898KYN_004, of the Italian Ministry of University and Research (MIUR). The research leading to these results was co-financed also by the European Community's Regional Development Fund in the framework of the Competence Centre Programme of Enterprise Estonia under project no. EU30002 carried out by the Bio-Competence Centre of Healthy Dairy Products (Tartu, Estonia), and by the Targeted Finance Projects $1080045 \mathrm{~s} 07$ and $0170165 \mathrm{~s} 08$.

\section{REFERENCES}

AIA (Associazione Italiana Allevatori). 2009. Milk recording activity: Official Statistics. Associazione Italiana Allevatori (AIA), Rome, Italy.
Aleandri, R., J. C. Schneider, and L. G. Buttazzoni. 1989. Evaluation of milk for cheese production based on milk characteristics and Formagraph measures. J. Dairy Sci. 72:1967-1975.

Brown, R. J., and S. K. Collinge. 1986. Actual milk coagulation time and inverse of chymosin activity. J. Dairy Sci. 69:956-958.

Cassandro, M., A. Comin, M. Ojala, R. Dal Zotto, M. De Marchi, L. Gallo, P. Carnier, and G. Bittante. 2008. Genetic parameters of milk coagulation properties and their relationships with milk yield and quality traits in Italian Holstein cows. J. Dairy Sci. 91:371-376.

Cecchinato, A., M. De Marchi, L. Gallo, G. Bittante, and P. Carnier. 2009. Mid-infrared spectroscopy predictions as indicator traits in breeding programs for enhanced coagulation properties of milk. J. Dairy Sci. 92:5304-5313.

Dal Zotto, R., M. De Marchi, A. Cecchinato, M. Penasa, M. Cassandro, P. Carnier, L. Gallo, and G. Bittante. 2008. Reproducibility and repeatability of measures of milk coagulation properties and predictive ability of mid-infrared reflectance spectroscopy. J. Dairy Sci. 91:4103-4112.

De Marchi, M., G. Bittante, R. Dal Zotto, C. Dalvit, and M. Cassandro. 2008. Effect of Holstein Friesian and Brown Swiss breeds on quality of milk and cheese. J. Dairy Sci. 91:4092-4102.

De Marchi, M., C. C. Fagan, C. P. O'Donnell, A. Cecchinato, R. Dal Zotto, M. Cassandro, M. Penasa, and G. Bittante. 2009. Prediction of coagulation properties, titratable acidity, and $\mathrm{pH}$ of bovine milk using mid-infrared spectroscopy. J. Dairy Sci. 92:423-432.

Hallén, E., T. Allmere, J. Näslund, A. Andrén, and A. Lundén. 2007. Effect of genetic polymorphism of milk proteins on rheology of chymosin-induced milk gels. Int. Dairy J. 17:791-799.

Hallén, E., A. Lundén, A.-M. Tyrisevä, M. Westerlind, and A. Andrén. 2010. Composition of poorly and non-coagulating bovine milk and effect of calcium addition. J. Dairy Res. 77:398-403.

ICAR (International Committee for Animal Recording). 2009. International agreement of recording practices. Guidelines approved by the General Assembly held in Niagara Falls, USA 18 June 2008.

Ikonen, T., K. Ahlfors, R. Kempe, M. Ojala, and O. Ruottinen. 1999. Genetic parameters for the milk coagulation properties and prevalence of noncoagulating milk in Finnish dairy cows. J. Dairy Sci. $82: 205-214$.

Ikonen, T., S. Morri, A.-M. Tyrisevä, O. Ruottinen, and M. Ojala. 2004. Genetic and phenotypic correlations between milk coagulation properties, milk production traits, somatic cell count, casein content, and pH of milk. J. Dairy Sci. 87:458-467.

ISO/IDF (International Standards Organization/International Dairy Federation). 2007. Milk-Determination of total milk-clotting activity by bovine rennets. ISO 11815/IDF 157. International Dairy Federation, Brussels, Belgium.

Jacob, M., D. Jaros, and H. Rohm. 2010. The effect of coagulant type on yield and sensory properties of semihard cheese from laboratory, pilot and commercial scale productions. Int. J. Dairy Technol. $63: 370-380$.

Johnson, M. E., C. M. Chen, and J. J. Jaeggi. 2001. Effect of rennet coagulation time on composition, yield, and quality of reduced-fat Cheddar cheese. J. Dairy Sci. 84:1027-1033.

Jõudu, I. 2008a. Effect of milk protein composition and genetic polymorphism on milk rennet coagulation properties. $\mathrm{PhD}$ Dissertation. Estonian University of Life Sciences, Tartu, Estonia. Accessed Jan. 15, 2011. http://dspace.emu.ee/jspui/bitstream/10492/113/1/ Thesis_Joudu_2008.pdf.

Jõudu, I., M. Henno, T. Kaart, T. Püssa, and O. Kärt. 2008b. The effect of milk proteins contents on the rennet coagulation properties of milk from individual dairy cows. Int. Dairy J. 18:964-967.

Karlsson, A. O., R. Ipsen, and Y. Ardö. 2007. Rheological properties and microstructure during rennet induced coagulation of UF concentrated skim milk. Int. Dairy J. 17:674-682.

Klandar, A. H., A. Lagaude, and D. Chevalier-Lucia. 2007. Assessment of the rennet coagulation of skim milk: A comparison of methods. Int. Dairy J. 17:1151-1160.

Kübarsepp, I., M. Henno, O. Kärt, and T. Tupasela. 2005a. A comparison of the methods for determination of the rennet coagulation properties of milk. Acta Agric. Scand. A Anim. Sci. 55:145-148. 
Kübarsepp, I., M. Henno, H. Viinalass, and D. Sabre. 2005b. Effect of $\kappa$-casein and $\beta$-lactoglobulin genotypes on the milk rennet coagulation properties. Agron. Res. 3:55-64.

Laporte, M. F., R. Martel, and P. Paquin. 1998. The near-infrared optic probe for monitoring rennet coagulation in cow's milk. Int. Dairy J. 8:659-666.

Lucey, J. A. 2002. Formation and physical properties of milk protein gels. J. Dairy Sci. 85:281-294.

Martin, B., J.-F. Chamba, J.-B. Coulon, and E. Perreard. 1997. Effect of milk chemical composition and clotting characteristics on chemical and sensory properties of Reblochon de Savoie cheese. J. Dairy Res. 64:157-162.

Ng-Kwai-Hang, K. F., I. Politis, R. I. Cue, and A. S. Marziali. 1989 Correlations between coagulation properties of milk and cheese yielding capacity and cheese composition. Can. Inst. Food Sci. Technol. J. 22:291-294.

O'Callaghan, D. J., C. P. O'Donnell, and F. A. Payne. 2002. Review of systems for monitoring curd setting during cheesemaking. Int. J. Dairy Technol. 55:65-74.
Pretto, D., and M. Cassandro. 2010. Estimation of economic values for milk production, SCS and milk coagulation properties in Italian Holstein Friesian dairy cattle. Page 325 in Proc. 9th World Congr. Genet. Appl. Livest. Prod., Leipzig, Germany. German Society for Animal Science, Giessen, Germany.

Tyrisevä, A.-M., T. Vahlsten, O. Ruottinen, and M. Ojala. 2004 Non-coagulation of milk in Finnish Ayrshire and Holstein-Friesian cows and effect of herds on milk coagulation ability. J. Dairy Sci. $87: 3958-3966$.

Vallas, M., H. Bovenhuis, T. Kaart, K. Pärna, H. Kiiman, and E. Pärna. 2010. Genetic parameters for milk coagulation properties in Estonian Holstein cows. J. Dairy Sci. 93:3789-3796.

Wedholm, A., L. B. Larsen, H. Lindmark-Månsson, A. H. Karlsson, and A. Andrén. 2006. Effect of protein composition on the cheesemaking properties of milk from individual dairy cows. J. Dairy Sci. 89:3296-3305.

Zannoni, M., and S. Annibaldi. 1981. Standardization of the renneting ability of milk by Formagraph. Sci. Tecn. Latt. Cas. 32:79-94. 